Pacific Journal of Mathematics

CONTRACTIONS OF FUNCTIONS AND THEIR FOURIER
SERIES SERIES 


\title{
CONTRACTIONS OF FUNCTIONS AND THEIR FOURIER SERIES
}

To Professor U. N. Singh on his $49^{\text {th }}$ birthday

\author{
B. S. YADAV
}

The object of the present paper is to define a new type of contraction, called 'Shrivel', of a function and to prove a theorem on the absolute convergence of its Fourier series. Our theorem is similar to a theorem of $M$. Kinukawa, but as it is shown in the end the two results are essentially different. The original results in this direction are due to $A$. Beurling and R. P. Boas.

According to Beurling [1] a function $g$ is said to be a contraction of function $f$ if $|g(x)-g(y)| \leqq A|f(x)-f(y)|$, for all $x, y$, where $A$ is an absolute constant. We shall assume throughout that the functions $f$ and $g$ are each $L$ - integrable in $(-\pi, \pi)$ and periodic with the period $2 \pi$. We shall further let

$$
f(x) \sim \frac{1}{2} a_{0}+\sum_{k=1}^{\infty}\left(a_{k} \cos k x+b_{k} \sin k x\right)
$$

and

$$
g(x) \sim \frac{1}{2} c_{0}+\sum_{k=}^{\infty}\left(c_{k} \cos k x+d_{k} \sin k x\right) .
$$

Kinukawa [3] has proved the following

TheOREM 1. Let $f$ and $g$ be each continuous and $g$ be a contraction of $f$, or more generally let $f, g \in L_{2}$ and

$$
\int_{-\pi}^{\pi}|g(x+h)-g(x)|^{2} d x \leqq \int_{-\pi}^{\pi}|f(x+h)-f(x)|^{2} d x, \text { for all } h .
$$

If

$$
\sum_{n=1}^{\infty} n^{-3 \alpha / 2}\left(\sum_{k=1}^{n} k^{2} p_{k}^{2}\right)^{\alpha / 2}<\infty
$$

and

$$
\sum_{n=1}^{\infty} n^{-\alpha / 2}\left(\sum_{k=n+1}^{\infty} p_{k}^{2}\right)^{\alpha / 2}<\infty,
$$

where $p_{k}^{\alpha}=\left|a_{k}\right|^{\alpha}+\left|b_{k}\right|^{\alpha}$ and $0<\alpha \leqq 2$, then

$$
\sum_{k=1}^{\infty}\left(\left|c_{k}\right|^{\alpha}+\left|d_{k}\right|^{\alpha}\right)<\infty
$$


The case $\alpha=1$ in this theorem is the theorem of Boas [2], which in turn is a generalization of a theorem of Beurling [1] on the absolute convergence of Fourier series.

However, it has been shown by Leindler [4] and Sunouchi [5] ${ }^{1}$ that the conditions (1) and (2) are equivalent. In fact, a more general result has been proved by $R$. Askey in his not yet published work which we shall need later and hence state here in the form of the following

LemMA $^{1}$. Let $s>0,0<p<1, a_{k}>0$. There are constants $K=$ $K(p, r, s)>0$ such that

$$
\sum_{n=1}^{\infty} n^{r}\left[n^{-s} \sum_{k=1}^{n} k^{s} a_{k}\right]^{p} \geqq K \sum_{n=1}^{\infty} n^{r}\left(\sum_{k=n}^{\infty} a_{k}\right)^{p}, \quad r>-1 ;
$$

and

$$
\sum_{n=1}^{\infty} n^{r}\left(\sum_{k=n}^{\infty} a_{k}\right)^{p} \geqq K \sum_{k=1}^{\infty} n^{r}\left[n^{-s} \sum_{k=1}^{n} k^{s} a_{k}\right]^{p}, \quad r<p s-1 .
$$

The object of this paper is to prove Theorem 2 which is similar to Theorem 1; but as we shall see in the end the two theorems are independent of each other. Before we can state our result precisely, we need introduce a couple of notations and a definition.

We put

$$
\Delta_{t}^{m} f(x)=\sum_{k=0}^{m}(-1)^{k} C_{m}^{k} f[x+(m-2 k) t]
$$

and

$$
L^{(m)}(h, x, f)=\frac{1}{h} \int_{0}^{h} \Delta_{t}^{m} f(x) d t
$$

Definition. We shall call a function $g$ a 'shrivel' of order $m$ of a function $f$ if

$$
\left|L^{(m)}(h, x, g)\right| \leqq A\left|L^{(m)}(h, x, f)\right|,
$$

for all $x$ and for all $h>0$.

We shall prove the following

THEOREM 2. If $g$ is a shrivel of order $m$ of $f$, or more generally, if

1 The author thanks the referee for pointing out to him these references and the unpublished work of $R$. Askey to show the equivalence of the conditions (1) and (2) which he missed in his original text of the paper. 


$$
\int_{-\pi}^{\pi}\left|L^{(m)}(h, x, g)\right|^{2} d x \leqq \int_{-\pi}^{\pi}\left|L^{(m)}(h, x, f)\right|^{2} d x,
$$

and if (2) holds, then the conclusion (3) remains valid.

Before we proceed for the proof, we mark that for $0<|h| \leqq \pi$,

$$
\left|L^{(m)}(h, x, f)\right| \leqq \frac{A(m)}{|h|} \int_{-\pi}^{\pi}|f(t)| d t ;
$$

and hence $L^{(m)}(h, x, f)$ is a bounded function of $x$ for fixed $h$ and $f$. $[A(m)$ denotes here, as also in the sequel, a constant depending on $m$ but not necessarily the same everywhere.] Therefore $L^{(m)}(h, x, f) \in L_{2}$. The same is true about $L^{(m)}(h, x, g)$ also. Thus the condition ' $g$ is a shrivel of order $m$ of $f$ ' does imply (4). Obviously, the converse is not true.

Again, it follows from the lemma that the condition (2) is equivalent to the condition

$$
\sum_{n=1}^{\infty} n^{-(m+1 / 2) \alpha}\left(\sum_{k=1}^{n} k^{2 m} p_{k}^{2}\right)^{\alpha / 2}<\infty,
$$

and this is what we shall need in the proof of our theorem .

Proof. We can obtain by simple calculations that, for an even $m$,

$$
\Delta_{t}^{m} g(x) \sim(-1)^{m / 2} 2^{m} \sum_{k=1}^{\infty}\left(c_{k} \cos k x+d_{k} \sin k x\right) \sin ^{m} k t ;
$$

and hence

$$
L^{(m)}(h, x, g) \sim(-1)^{m / 2} 2^{m} \sum_{k=1}^{\infty}\left(c_{k} \cos k x+d_{k} \sin k x\right)\left(\frac{1}{h} \int_{0}^{h} \sin ^{m} k t d t\right) .
$$

Similarly for an odd $m$,

$$
L^{(m)}(h, x, g) \sim(-1)^{(m-1) / 2} 2^{m} \sum_{k=1}^{\infty}\left(d_{k} \cos k x-c_{k} \sin k x\right)\left(\frac{1}{h} \int_{0}^{h} \sin ^{m} k t d t\right) .
$$

Therefore by Parseval's theorem

$$
\begin{aligned}
\sum_{k=1}^{\infty} q_{k}^{2}\left(\frac{1}{h} \int_{0}^{h} \sin ^{m} k t d t\right)^{2} & =A(m) \int_{-\pi}^{\pi}\left|L^{(m)}(h, x, g)\right|^{2} d x \\
& \leqq A(m) \int_{-\pi}^{\pi}\left|L^{(m)}(h, x, f)\right|^{2} d x \\
& =A(m) \sum_{k=1}^{\infty} p_{k}^{2}\left(\frac{1}{h} \int_{-\pi}^{\pi} \sin ^{m} k t d t\right)^{2},
\end{aligned}
$$

where 


$$
q_{k}^{2}=c_{k}^{2}+d_{k}^{2}
$$

Now taking $h=\pi / 2^{n+1}$ and observing that

(i) $\sin k t>0$, and is an increasing function of $t$ for $\pi / 2^{n+2} \leqq$ $t \leqq \pi / 2^{n+1} ; 2^{n-1}<k \leqq 2^{n}$,

(ii) $\sin ^{2} k \pi / 2^{n+2}>\sin ^{2} \pi / 8$ for $2^{n-1}<k \leqq 2^{n}$, we get

$$
\begin{aligned}
\sum_{k=1}^{\infty} q_{k}^{2} & \left(\frac{2^{n+1}}{\pi} \int_{0}^{\pi / 2^{n+1}} \sin ^{m} k t d t\right)^{2} \\
& \geqq \sum_{k=2^{n-1}+1}^{2^{n}} q_{k}^{2}\left(\frac{2^{n+1}}{\pi} \int_{0}^{\pi / 2^{n+1}} \sin ^{m} k t d t\right)^{2} \\
& \geqq \sum_{k=2^{n-1}+1}^{2^{n}} q_{k}^{2}\left(\frac{2^{n+1}}{\pi} \int_{\pi / 2^{n+2}}^{\pi / 2^{n+1}} \sin ^{m} k t d t\right)^{2} \\
& \geqq \sum_{k=2^{n-1}+1}^{2^{n}} q_{k}^{2}\left(\frac{2^{n+1}}{\pi} \cdot \frac{\pi}{2^{n+2}} \cdot \sin ^{m} \frac{k \pi}{2^{n+1}}\right)^{2} \\
& \geqq A(m) \sum_{k=2^{n-1}+1}^{2^{n}} q_{k}^{2} .
\end{aligned}
$$

Also, by Hölder's inequality

$$
\sum_{k=2^{n-1}+1}^{2^{n}} q_{k}^{\alpha} \leqq 2^{(n-1)(1-\alpha / 2)}\left(\sum_{k=2^{n-1}+1}^{2^{n}} q_{k}^{2}\right)^{\alpha / 2} .
$$

Therefore we obtain from (6), (7) and (8)

$$
\begin{aligned}
\sum_{n=2}^{\infty} q_{n}^{\alpha}= & \sum_{n=1}^{\infty} \sum_{k=2^{n-1}+1}^{2^{n}} q_{k}^{\alpha} \\
\leqq & A(m, \alpha) \sum_{n=1}^{\infty} 2^{n(1-\alpha / 2)}\left[\sum_{k=1}^{\infty} p_{k}^{2}\left(\frac{2^{n+1}}{\pi} \int_{0}^{\pi / 2^{n+1}} \sin ^{m} k t d t\right)^{2}\right]^{2 / 2} \\
\leqq & A(m, \alpha)\left[\sum_{n=1}^{\infty} 2^{n(1-\alpha / 2)}\left(\sum_{k=1}^{2 n} p_{k}^{2} \sin ^{2 m} \frac{k \pi}{2^{n+1}}\right)^{\alpha / 2}\right. \\
& \left.+\sum_{n=1}^{\infty} 2^{n(1-\alpha / 2)}\left(\sum_{k=2^{n}+1}^{\infty} p_{k}^{2}\right)^{\alpha / 2}\right] \\
\leqq & A(m, \alpha)\left[\sum_{n=1}^{\infty} 2^{n(1-\alpha / 2-m \alpha)}\left(\sum_{k=1}^{2^{n}} k^{2 m} p_{2}^{2}\right)^{\alpha / 2}\right. \\
& \left.+\sum_{n=1}^{\infty} 2^{n(1-\alpha / 2)}\left(\sum_{k=2^{n}+1}^{\infty} p_{k}^{2}\right)^{\alpha / 2}\right]
\end{aligned}
$$

Now it is not difficult to see that the two series within the square brackets are covergent if and only if (5) and (2) hold respectively. See Szàsz [6], Lemma 2.2. Since

$$
\left|c_{k}\right|^{\alpha} \leqq q_{k}^{\alpha}, \quad\left|d_{k}\right|^{\alpha} \leqq q_{k}^{\alpha},
$$

(3) follows; and hence the proof. 
To prove that the result of Theorem 2 is completely independent of Kinukawa's Theorem 1, we first see that $g$ is a shrivel of order 1 of $f$ if for all $x$ and all $h>0$,

(9) $\left|\int_{0}^{h}\{g(x+t)-g(x-t)\} d t\right| \leqq A\left|\int_{0}^{h}\{f(x+t)-f(x-t)\} d t\right|$.

Now consider the $2 \pi$ - periodic function defined by

$$
\begin{aligned}
f(x) & =0 \text { for } \quad-\pi<x<0, \\
& =\sin 2 x \quad \text { for } 0 \leqq x \leqq \pi .
\end{aligned}
$$

Also let

$$
\begin{aligned}
\phi(x) & =x \quad \text { for } \quad x<0 \\
& =x-x^{2} \text { for } x \geqq 0,
\end{aligned}
$$

and let $g(x)=\phi(f(x))$ for all $x$. The function $\phi$ is differentiable and has a bounded derivative on the interval $[-1,1]$. Hence $\phi$ belongs tc the class Lip 1 on this interval, whence, $g$ is a contraction of $f$ in Beurling's sense. On the other hand,

$$
\int_{0}^{\pi}\{f(t)-f(-t)\} d t=\int_{0}^{\pi} \sin 2 t d t=0,
$$

while

$$
\begin{aligned}
\int_{0}^{\pi}\{g(t)-g(-t)\} d t & =\int_{0}^{\pi} g(t) d t \\
& =\int_{0}^{\pi / 2}\left(\sin 2 t-\sin ^{2} 2 t\right) 2 t+\int_{\pi / 2}^{\pi} \sin 2 t d t \\
& =-\int_{0}^{\pi / 2} \sin ^{2} 2 t d t \neq 0,
\end{aligned}
$$

so that (9) is not satisfied for any $A$ when $x=0$ and $h=\pi$.

Conversely, since (9) can be satisfied when $f, g$ are merely integrable, (9) does not imply that $g$ is a contraction of $f$.

Finally we remark that Theorem 2 has its usual dual.

\section{REFERENCES}

1. A. Beurling, On the spectral synthesis of bounded functions, Acta Math. 81 (1949), 225-238.

2. R. P. Boas, Beurling's test for absolute convergence of Fourier series, Bull. Amer. Math. Soc. 66 (1960), 24-27.

3. M. Kinukawa, Contractions of Fourier coefficients and Fourier integrals, J. Analyse Math. 8 (1960/1961), 377-406. 
4. L. Leindler, Über verschiendene kenevergenzarten trigonometrischer Rein, Acta Sci. Math. (Szeged) 25 (1964), 233-249.

5. G. Sunouchi, On the convolution algebra of Beurling, Tôhoku Math. J. (2) (1967), 303-310.

6. O. Szàsz, Fourier series and mean moduli of continuity, Trans. Amer. Math.īSoc. 42 (1937), 366-395.

Received October 8, 1968.

Sardar Patel UNIVERSity

VallabH Vidyanagar, Gujarat, India 


\title{
PACIFIC JOURNAL OF MATHEMATICS
}

\author{
EDITORS
}

\author{
H. ROYDEN \\ Stanford University \\ Stanford, California \\ RICHARD PIERCE \\ University of Washington \\ Seattle, Washington 98105
}

\author{
J. DUGUNDJI \\ Department of Mathematics \\ University of Southern California \\ Los Angeles, California 90007 \\ BASIL GORDON \\ University of California \\ Los Angeles, California 90024
}

\section{ASSOCIATE EDITORS}

E. F. BECKENBACH
B. H. NeumanN

F. WOLF
K. YoshidA

\section{SUPPORTING INSTITUTIONS}

\author{
UNIVERSITY OF BRITISH COLUMBIA \\ CALIFORNIA INSTITUTE OF TECHNOLOGY \\ UNIVERSITY OF CALIFORNIA \\ MONTANA STATE UNIVERSITY \\ UNIVERSITY OF NEVADA \\ NEW MEXICO STATE UNIVERSITY \\ OREGON STATE UNIVERSITY \\ UNIVERSITY OF OREGON \\ OSAKA UNIVERSITY \\ UNIVERSITY OF SOUTHERN CALIFORNIA
}

\author{
STANFORD UNIVERSITY \\ UNIVERSITY OF TOKYO \\ UNIVERSITY OF UTAH \\ WASHINGTON STATE UNIVERSITY \\ UNIVERSITY OF WASHINGTON

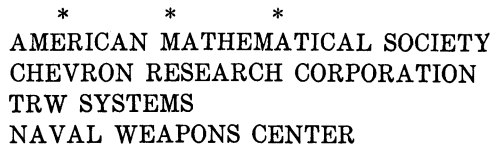

The Supporting Institutions listed above contribute to the cost of publication of this Journal, but they are not owners or publishers and have no responsibility for its content or policies.

Mathematical papers intended for publication in the Pacific Journal of Mathematics should be in typed form or offset-reproduced, double spaced with large margins. Underline Greek letters in red, German in green, and script in blue. The first paragraph or two must be capable of being used separately as a synopsis of the entire paper. It should not contain references to the bibliography. Manuscripts, in duplicate if possible, may be sent to any one of the four editors. Please classify according to the scheme of Math. Rev. 36, 1539-1546. All other communications to the editors should be addressed to the managing editor, Richard Arens, University of California, Los Angeles, California, 90024.

50 reprints are provided free for each article; additional copies may be obtained at cost in multiples of 50 .

The Pacific Journal of Mathematics is published monthly. Effective with Volume 16 the price per volume (3 numbers) is $\$ 8.00$; single issues, $\$ 3.00$. Special price for current issues to individual faculty members of supporting institutions and to individual members of the American Mathematical Society: $\$ 4.00$ per volume; single issues $\$ 1.50$. Back numbers are available.

Subscriptions, orders for back numbers, and changes of address should be sent to Pacific Journal of Mathematics, 103 Highland Boulevard, Berkeley, California, 94708.

PUBLISHED BY PACIFIC JOURNAL OF MATHEMATICS, A NON-PROFIT CORPORATION

Printed at Kokusai Bunken Insatsusha (International Academic Printing Co., Ltd.), 7-17, Fujimi 2-chome, Chiyoda-ku, Tokyo, Japan. 


\section{Pacific Journal of Mathematics}

\section{Vol. 31, No. $3 \quad$ BadMonth, 1969}

George E. Andrews, On a calculus of partition functions .................. 555

Silvio Aurora, A representation theorem for certain connected rings ............ 563

Lawrence Wasson Baggett, A note on groups with finite dual spaces ............. 569

Steven Barry Bank, On majorants for solutions of algebraic differential equations in regions of the complex plane ............................... 573

Klaus R. Bichteler, Locally compact topologies on a group and the corresponding continuous irreducible representations ......................... 583

Mario Borelli, Affine complements of divisors ....................... 595

Carlos Jorge Do Rego Borges, A study of absolute extensor spaces ............. 609

Bruce Langworthy Chalmers, Subspace kernels and minimum problems in Hilbert

spaces with kernel function ...................................... 619

John Dauns, Representation of L-groups and F-rings................. 629

Spencer Ernest Dickson and Kent Ralph Fuller, Algebras for which every

indecomposable right module is invariant in its injective envelope ...........

Robert Fraser and Sam Bernard Nadler, Jr., Sequences of contractive maps and fixed

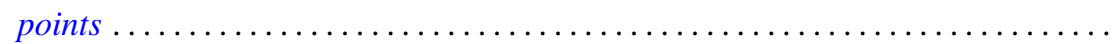

Judith Lee Gersting, A rate of growth criterion for universality of regressive

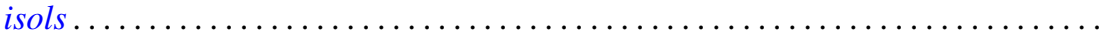

Robert Fred Gordon, Rings in which minimal left ideals are projective ............

Fred Gross, Entire functions of several variables with algebraic derivatives at certain algebraic points

W. Charles (Wilbur) Holland Jr. and Stephen H. McCleary, Wreath products of ordered permutation groups .........................

W. J. Kim, The Schwarzian derivative and multivalence .................. 717

Robert Hamor La Grange, Jr., On $(\mathrm{m}-\mathrm{n})$ products of Boolean algebras ......... 725

Charles D. Masiello, The average of a gauge ........................ 733

Stephen H. McCleary, The closed prime subgroups of certain ordered permutation

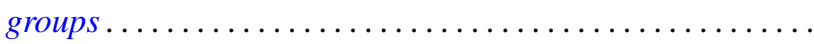

Richard Roy Miller, Gleason parts and Choquet boundary points in convolution measure algebras ...............................

Harold L. Peterson, Jr., On dyadic subspaces ........................ 773

Derek J. S. Robinson, Groups which are minimal with respect to normality being intransitive........................................... 777

Ralph Edwin Showalter, Partial differential equations of Sobolev-Galpern type . . . 787

David Slepian, The content of some extreme simplexes ................... 795

Joseph L. Taylor, Noncommutative convolution measure algebras ............. 809

B. S. Yadav, Contractions of functions and their Fourier series ............... 827

Lindsay Nathan Childs and Frank Rimi DeMeyer, Correction to automorphisms of separable algebras" ....................... 833

Moses Glasner and Richard Emanuel Katz, Correction to: "Function-theoretic degeneracy criteria for Riemannian manifolds".............

Satish Shirali, Correction to: "On the Jordan structure of complex Banach

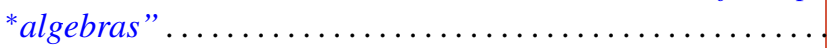

